\title{
INMIGRACIÓN, INTEGRACIÓN E INTERACCIÓN EN EL FUTURO DEL MEDITERRÁNEO
}

\section{IMMIGRATION, INTEGRATION E INTERACTION IN THE FUTURE OF THE MEDITERRANEAN}

\author{
Jamal Benamar \\ Universidad Abdelmalek Essaâdi, Tánger. Marruecos/Morocco \\ byamal2000@yahoo.fr
}

Recibido/Received: 18/05/09

Aceptado/Accepted: 07/08/09

\section{RESUMEN}

Europa es hoy el primer continente en materia de inmigración internacional, en el 2005 contaba con 65 M de inmigrantes internacionales, seguida por Asia 53 M y América del Norte con 44 M según la Oficina Internacional del Trabajo (OIT) en el 2004, 56 millones de inmigrantes vivían en Europa de los cuales 27,5 millones son activos. Los Estados europeos que eran tradicionalmente países de emigración como Italia, España o Portugal son hoy países de inmigración. Estos movimientos de población, de carácter provisional, permanente, económico o en relación con la reagrupación familiar, no dejan indiferentes a los estados de la Unión Europea, más aún, les obliga a pensar políticas de integración para asegurar la paz social del conjunto de sus respectivas sociedades cada vez más multiétnicas y multiconfesionales.

\section{PALABRAS CLAVE}

Inmigración, integración, interacción, paz social, espacio mediterráneo.

\begin{abstract}
Europe is today the first continent in the matter of international immigration, in the 2005 counted on 65 Ms of international immigrants, followed by Asia $53 \mathrm{Ms}$ and North America with $44 \mathrm{Ms}$ according to the International Labour Organization (ILO) in the 2004, 56 millions immigrants lived in Europe on which 27.5 millions are active. The European States that were traditionally countries of emigration like Italy, Spain or Portugal are today immigration countries. These movements of population, provisional, permanent, economic character or in relation to the familiar regrouping do not leave indifferent the states of the European Union, but even, it forces to think integration policies in order to assure social peace the set of its respective multiethnic and multi religion societies.
\end{abstract}

\section{KEYWORDS}

Immigration, integration, interaction, social peace, Mediterranean space.

\section{LA EUROPA DE LA INMIGRACIÓN}

Desde el Tratado de Ámsterdam, de 1997 ratificado en 1999, las políticas de inmigración han dejado de ser competencia exclusiva de los Estados miembros. Así pues, 
la inmigración y la integración constituyen una de las tres prioridades de la acción de la Unión Europea definidas durante el Consejo Europeo de Tampere en octubre de 1999.

Recordando sus conclusiones de junio del 2003 (Salónica) y noviembre del 2004 (Bruselas), el Consejo Europeo ha acogido favorablemente el establecimiento de unos principios básicos comunes para la política de los estados miembros en materia de integración de los inmigrantes. Estos serán la base de un marco global de integración de los inmigrantes que tenga en cuenta la diversidad jurídica, política, económica, social y cultural de los Estados miembros. Deberán elaborarse a la luz de las experiencias comunes.

Sin embargo, los modelos de integración de las minorías puestos en marcha por los países europeos siguen siendo tributarios de la historia de cada Estado. Cada Estado define su propio marco legislativo y reglamentario (derechos civiles, sociales y políticos, libertades públicas) que constituye su marco nacional. La integración esta subordinada al acceso de los extranjeros a esas disposiciones, a las "reglas del juego social".

La evolución de los flujos migratorios interroga a cada país europeo sobre el hueco que esta dispuesto a hacer a los inmigrantes en la sociedad, así como las medidas destinadas a facilitar su integración o su inserción o su inclusión en el mundo del trabajo. También se plantean a estos países los problemas derivados del alojamiento del inmigrante, de sus modos de vida (su cultura), de su salud, de la práctica de su religión, de su educación, de su naturalización, de su participación en la vida política y su distribución espacial a diferentes niveles.

El desafío de la integración consiste en otorgar a los inmigrantes de origen extranjero, residentes de forma permanente en los países europeos, "medios verdaderos para poder participar en la vida nacional y europea". Ahora bien, la necesidad de ofrecer a los inmigrantes derechos y obligaciones comparables a los ciudadanos de la Unión, en la vida cultural, social, política o económica, necesita unas "políticas públicas" y la puesta en marcha de medidas de promoción, de ayuda y de acompañamiento dentro de un ancho espacio de tiempo que difieren todavía de un país al otro.

En la realidad, la Unión Europea se encamina hacia un proceso de "comunitarización" de las políticas migratorias. Para abordar el tema de la integración comunitaria es necesario conocer primero las políticas de inmigración para intentar comprender después las políticas de integración de inmigrantes puestas en marcha en los principales países europeos, en los términos expuestos anteriormente (igualdad de oportunidades), y los efectos de esas políticas sobre las poblaciones originarias de la inmigración. Algunos ejemplos nos servirán para abordar la realidad de estas políticas de integración.

\section{POLÍTICAS DE INMIGRACIÓN EN EUROPA}

\section{Aclaraciones}

Si el concepto de « inmigración » puede emplearse siempre que nos referimos a un movimiento de población hacia un país de acogida y con intención de instalarse, el termino « inmigrante » es impreciso para ser utilizado sin algún tipo de riesgo.

Se define como inmigrante "toda persona nacida en el extranjero, de nacionalidad extranjera, que vive en el territorio nacional”. Pero en la realidad, la acepción más 
utilizada para este término es más amplia. De hecho, el término de inmigrante parece más bien ligado a la diferencia de origen y no a un estatuto jurídico (al contrario de la noción de extranjero). Esto traduce un inconsciente colectivo que esconde una cierta imagen del mundo que opone Europa, Occidente (países ricos): el Norte; a los otros pueblos de la tierra (países pobres): El Sur.

La visión del inmigrante es pues indisociable de todo aquel que viene del tercer mundo y de todo lo que le distingue de la realidad europea: modo de vida, religión, tradiciones, lengua, apellidos, color de piel, nivel de riqueza,...En la realidad, la noción de inmigrante parece más bien ligada a la "diferencia".

\section{POLÍTICAS SEGUIDAS POR LOS PAÍSES DE LA UNIÓN EUROPEA}

Aunque el fenómeno de la inmigración está generalizado en todos los países de la Unión Europea, la historia, los tipos y la amplitud del mismo difieren de un país a otro. Algunos países pioneros en inmigración como Francia, Alemania, Holanda, Bélgica y Gran Bretaña empezaron a importar mano de obra a partir de la década de los cincuenta. Otros países como Portugal, Grecia, España, Irlanda e Italia viven recientemente, aunque de manera intensa, el fenómeno de la inmigración.

\section{Evolución de la población de inmigrantes en Europa}

\begin{tabular}{lccccc}
\hline Año & $\begin{array}{c}\text { Estimación de } \\
\text { inmigrantes } \\
\text { internacionales }\end{array}$ & $\begin{array}{c}\text { Numero de } \\
\text { refugiados }\end{array}$ & $\begin{array}{c}\text { Población } \\
\text { (millares) }\end{array}$ & $\begin{array}{c}\text { Numero } \\
\text { estimado de } \\
\text { inmigrantes } \\
\text { varones }\end{array}$ & $\begin{array}{c}\text { \% de inmigrantes } \\
\text { sobre el total de } \\
\text { Ia población }\end{array}$ \\
\hline 1960 & 14244764 & 883268 & 424266 & 7357256 & 3,4 \\
\hline 1965 & 16662207 & 703203 & 443539 & 8675357 & 3,8 \\
\hline 1970 & 18783392 & 629945 & 458196 & 9831050 & 4,1 \\
\hline 1975 & 20170448 & 547829 & 471909 & 10560151 & 4,3 \\
\hline 1980 & 21894487 & 536692 & 482680 & 11361732 & 4,5 \\
\hline 1985 & 23471785 & 881800 & 489868 & 11999492 & 4,8 \\
\hline 1990 & 49381119 & 1317763 & 721390 & 23327018 & 6,9 \\
\hline 1995 & 55286554 & 3004855 & 727885 & 26128336 & 7,6 \\
\hline 2000 & 58216735 & 2486718 & 728462 & 27153068 & 8,8 \\
\hline 2005 & 64115850 & 2015932 & 728389 & 29851239 & \\
\hline
\end{tabular}

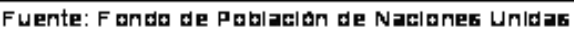

La Europa de las migraciones se ha transformado profundamente en estos últimos años. La diversificación es la palabra clave de esta dinámica. El número de las nacionalidades en cuestión sigue aumentando. Los flujos son más variados. Nuevas redes aparecen intentando burlar el control del flujo y se apoyan en las vías de naturaleza económica, cultural, étnica o religiosa. Europa no se escapa del fenómeno de mundialización de las corrientes migratorias al que asistimos actualmente, fenómeno que concierne a todos los continentes. 
A pesar de la suspensión de los flujos migratorios de mano de obra acaecida en la mayoría de los países europeos en los años 1973 y 1974 - tras la crisis petrolera - la movilidad no ha decrecido.

\begin{tabular}{|c|c|c|c|c|c|}
\hline \multirow[b]{2}{*}{ País o área } & \multicolumn{2}{|c|}{1990} & \multirow[b]{2}{*}{ País o área } & \multicolumn{2}{|c|}{2005} \\
\hline & $\begin{array}{c}\text { Núm. de } \\
\text { inmigrantes } \\
\text { (millones) }\end{array}$ & $\begin{array}{c}\text { Como } \% \text { del } \\
\text { total }\end{array}$ & & $\begin{array}{c}\text { Núm. de } \\
\text { inmigrantes } \\
\text { (millones) }\end{array}$ & $\begin{array}{c}\text { Como } \% \text { del } \\
\text { total }\end{array}$ \\
\hline EEUU & 23,3 & 15,0 & EEUU & 38,4 & 20,2 \\
\hline Rusia & 11,5 & 7,4 & Rusia & 12,1 & 6,4 \\
\hline India & 7,4 & 4,8 & Alemania & 10,1 & 5,3 \\
\hline Ucrania & 7,1 & 4,6 & Ucrania & 6,8 & 3,6 \\
\hline Pakistán & 6,6 & 4,2 & Francia & 6,5 & 3,4 \\
\hline Alemania & 5,9 & 3,8 & Arabia Saudí & 6,4 & 3,3 \\
\hline Francia & 5,9 & 3,8 & Canadá & 6,1 & 3,2 \\
\hline Arabia Saudí & 4,7 & 3,1 & India & 5,7 & 3,0 \\
\hline Canadá & 4,3 & 2,8 & Reino Unido & 5,4 & 2,8 \\
\hline Australia & 4,0 & 2,6 & España & 4,8 & 2,5 \\
\hline Irán & 3,8 & 2,5 & Australia & 4,1 & 2,2 \\
\hline Reino Unido & 3,8 & 2,4 & Pakistán & 3,3 & 1,7 \\
\hline Kazakhastan & 3,6 & 2,3 & Emiratos Árabes & 3,2 & 1,7 \\
\hline Hong Kong, SAR China & 2,2 & 1,4 & Hong Kong, SAR China & 3,0 & 1,6 \\
\hline Costa de Marfil & 2,0 & 1,3 & Israel & 2,7 & 1,4 \\
\hline Uzbekistan & 1,7 & 1,1 & Italia & 2,5 & 1,3 \\
\hline Argentina & 1,6 & 1,1 & Kazakhstan & 2,5 & 1,3 \\
\hline Israel & 1,6 & 1,1 & Costa de Marfil & 2,4 & 1,2 \\
\hline Kuwait & 1,6 & 1,0 & Jordania & 2,2 & 1,2 \\
\hline Suiza & 1,4 & 0,9 & Japón & 2,0 & 1,1 \\
\hline
\end{tabular}

Fuente: Trends in Total Migrant Stock: The 2005 Revision. United Nations

Un número importante de países de inmigración están enfrentados a los movimientos de población de una misma naturaleza: reagrupación familiar, estudiantes, trabajadores temporales y huída de cerebros. Nuevos efectos llamada han acelerado esta movilidad, en particular la demanda sectorial de mano de obra, la escasez en algunos países de competencias o talentos, y por fin la regularización extraordinaria de los inmigrantes ilegales. Al mismo tiempo, otros factores empujan a los candidatos a la salida a marcharse: desestabilización de regímenes pobres y poco democráticos, crecimiento de una población joven y sin empleo, atracción hacia el mito del modo de vida occidental.

Los tipos de migraciones se han transformado fuertemente. A los trabajadores extranjeros de los años de crecimiento les sucedió el inmigrante instalado, pero también el demandante de asilo, las nuevas generaciones inmigrantes (ya se cuenta con la segunda e incluso la tercera), el inmigrante "migratorio". La proximidad es más grande gracias a los medios de transportes más rápidos y menos caros y a los flujos mediáticos, culturales y económicos. Sin embargo, la migración se hace cada vez más difícil debido al cierre de las fronteras. Europa se quiere erigir en fortaleza.

Diversamente enfrentados a la mundialización de los flujos migratorios, los países de inmigración europeos han buscado a la vez dar respuestas nacionales al fenómeno y extraer las grandes líneas de su actuación de una mayor armonización a la escala europea. Pero, muy a menudo, las políticas de inmigración oscilan entre la "europeización" y el repliegue interior. Algunas iniciativas han sido llevadas a cabo con idea de convergencia, primero a escala intergubernamental, sea a nivel de algunos Estados y a modo experimental (acuerdos de Schengen cuya entrada en vigor efectiva fue en 1995), sea a nivel del conjunto de los Estados miembros (acuerdos de Trevi en Italia en 
1992 sobre la colaboración policial internacional: nace Europol y convenios de Dublín en Irlanda en 1990 relativo a las solicitudes de asilo), después a nivel de la Unión Europea (acuerdos de Ámsterdam y Tampere, en 1999), unos mecanismos de intercambios de experiencias y de datos funcionan ya (CIREA, 1998: Centro de Información, Investigación e Intercambios en materia de Asilo, dejó de existir en el 2002 a raíz de la aparición de la red de la UE para expertos en asilo llamada EURASIL; CIREFI, 1998: Centro de Información, Investigación e Intercambios sobre el Paso de Fronteras e Inmigración y EURODAC, 2000 : Banco informatizado de datos con huellas dactilares de refugiados y solicitantes de asilo; FRONTEX, 2004: Agencia Europea para la gestión de la cooperación operativa en las fronteras exteriores de los Estados miembros de la Unión Europea ), se dibujan unas políticas semejantes (al margen de las disposiciones relativas a los ciudadanos de la Unión, podemos citar la política común de los visados, las disposiciones relativas al derecho de asilo, a la reagrupación familiar y a la estancia).

Sin embargo, subsisten divergencias importantes que obstaculizan la existencia de una política europea de inmigración más concertada e introducen unos efectos perversos en las reglas del juego que suponen más homogeneidad.

Podemos mencionar algunas:

1. Las disparidades en el derecho a la adquisición de la nacionalidad: países en los que prima el Ius Soli u otros en los que prevalece el Ius Sanguinis, países que mantienen un equilibrio entre los dos, países con disposiciones específicas ligadas a un pasado colonial o a una pertenencia a un área cultural o geográfica. Cada una de esas diferencias, ligada a la historia, a la geografía, y a veces símbolo de la soberanía de los Estados, introduce modos de entrada muy diversos en la ciudadanía europea. ¿Pero como se puede definir una ciudadanía europea construida sobre la reciprocidad de los derechos entre Europeos y que se distingue fuertemente del estatuto de los no Europeos, fundada en la residencia y demandando una identidad común, cuando cada Estado tiene su propia definición de lo que es ser Europeo? Estos interrogantes pesan sobre la definición y la elaboración de la ciudadanía europea, ¿Ciudadanía multicultural o intercultural?

2. La diversidad en la aplicación del derecho de asilo: aunque se observa en toda Europa una generalización del asilo temporal (asilo territorial por medio de visados a corto plazo), es asombroso ver la gran variedad de los procesos, de las prácticas, de los criterios de entrega del estatuto de refugiado, hechos reveladores de la poca transparencia existente entre los países.

3. La fuerte dependencia de las políticas migratorias de los Estados con respecto a una opinión publica nacional a la vez cambiante, restrictiva y obsesionada por la seguridad. Estos fenómenos de opinión son a menudo fuente de amalgamas (solicitantes de asilo, clandestinos, terroristas, delincuentes) perjudiciales a una aprensión de los flujos (entradas) y las existencias (integración).

La ausencia de una política global a la escala europea sobre las cuestiones migratorias conduce a una serie de monólogos que se cruzan poco, ya que están hipotecados por la situación interior de los Estados y la obsesión de seguridad, estos dos elementos orientan la política de inmigración más hacia la regulación y el control de las fronteras y la lucha contra la inmigración ilegal que hacia la cooperación con los países de origen o de tránsito o a la integración de los inmigrantes. ¿Esto quiere decir que la "europeización" de la política migratoria ha fracasado? No, sólo quiere decir que ésta se encuentra en sus inicios. 


\subsection{La política de inmigración seguida por España}

España pasó de ser una tierra de emigración a ser un país de inmigración en la década de los ochenta. Esta evolución se explica por los cambios políticos y económicos consecutivos a la democracia, a la entrada en la Unión Europea y al crecimiento económico.

Con motivo de la evolución de la corriente migratoria que tuvo lugar en el país en los años 80 y como anticipación a la incorporación de España a la Unión Europea, porque se pensaba que podría ser una "mancha negra" en su ingreso en la UE, España estableció la primera regulación del derecho de extranjería mediante la Ley Orgánica 7/1985 sobre derechos y libertades de los extranjeros en España.

Esta ley resultó ser una norma restrictiva (entrada, permiso de trabajo y residencia, nada de preagrupación familiar, a veces negación de las prestaciones sociales), que no se ajustaba a los criterios imperantes en el marco comunitario e ineficaz ya que no conseguía frenar el flujo de inmigrantes.

Siguieron una serie de reformas de esta Ley (Ley Orgánica 4/2000, Ley 8/2000 y Ley 14/2003) que pretendían:

a) Reforzar los derechos y libertades de los inmigrantes y su integración social y laboral,

b) Reforzar el control de los flujos migratorios en adecuación con las directivas europeas en materia inmigratoria y establecer vías de expulsión de los "sin papeles",

c) Luchar contra las mafias y el tráfico ilegal de personas,

d) Reforzar la seguridad ciudadana y luchar contra la violencia doméstica,

e) Habilitar el acceso a la información de las administraciones por parte de las

Fuerzas y Cuerpos de Seguridad para luchar contra la inmigración ilegal,

f) Modificar las condiciones de la reagrupación familiar,

g) Recortar los derechos de los inmigrantes establecidos ilegalmente en España.

Según dice Maria Villena Rodríguez, de la Universidad de Sevilla, refiriéndose a la LOEx y sus sucesivos cambios: "es una Ley únicamente de represión y control de los inmigrantes ilegales, no de integración de los extranjeros, como dice su título."

La Secretaria de Estado, Consuelo Rumí, hizo unas declaraciones a la prensa el martes 15 de noviembre del 2005 en las que explicó que España y la UE están "reflexionando" sobre la necesidad de reformar la Ley de Extranjería para adaptarla a una nueva directiva que tiene como objetivo:

1. Facilitar la igualdad de oportunidades en el acceso al empleo, a la educación, a la vivienda,...

2. Permitir a los inmigrantes residentes legales en la UE desde al menos 5 años desplazarse por todos los países de la Unión,

3. Fomentar la cooperación al desarrollo en la próxima cumbre de Barcelona en diciembre próximo y en la Euroafricana prevista en Marruecos en el 2006. 


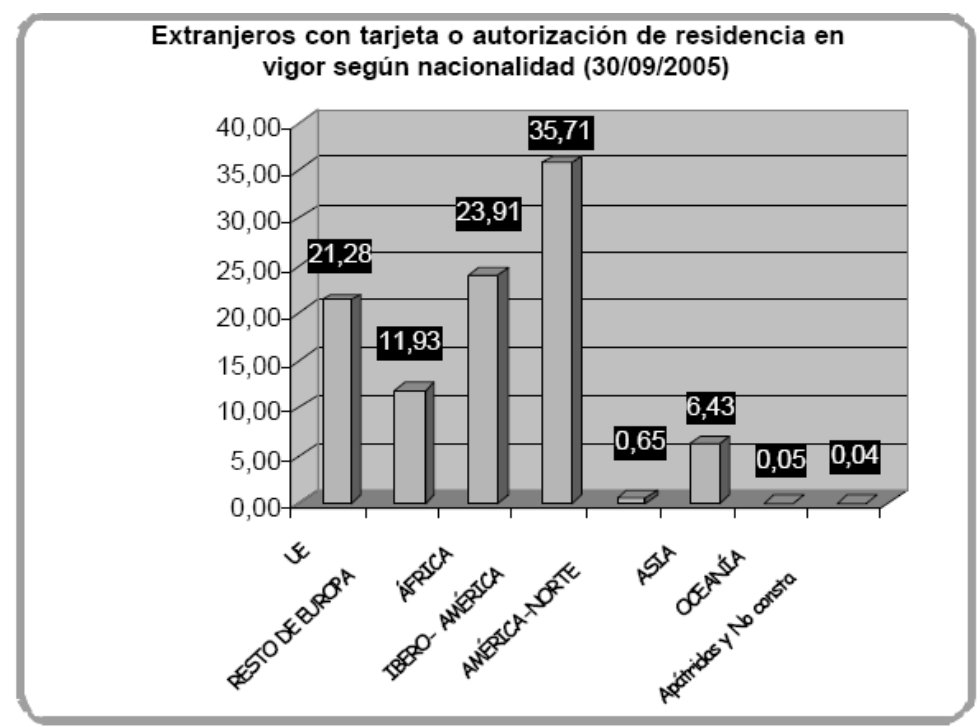

Elaboración propia. Fuente: Secretaria de Estado de Inmigración y Emigración, 2005

Marruecos representa el $76,20 \%$ de los inmigrantes procedentes del continente africano en el territorio nacional.

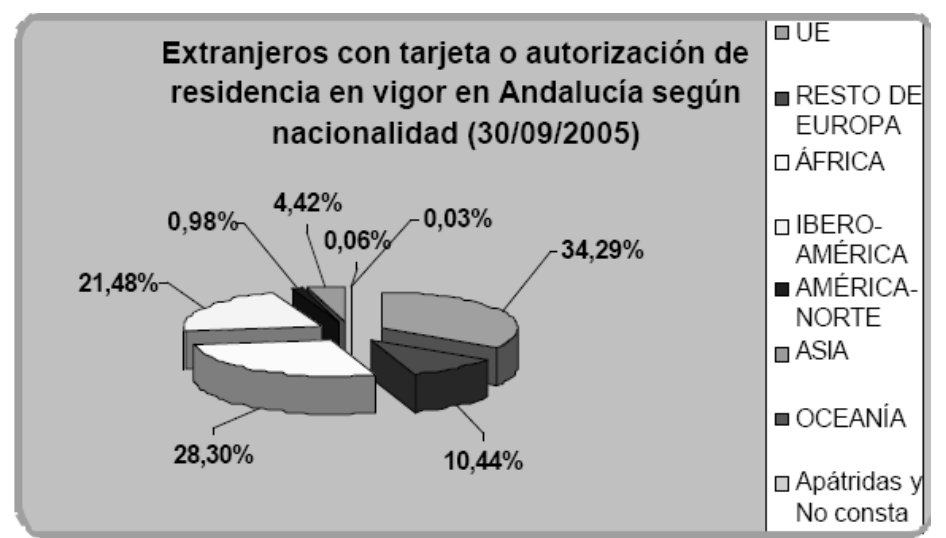

Elaboración propia. Fuente: Secretaria de Estado de Inmigración y Emigración, 2005

Marruecos representa el 78,74\% de los inmigrantes procedentes del continente africano en la Comunidad Autónoma de Andalucía.

\section{POLÍTICAS DE INTEGRACIÓN EUROPEAS}

\section{Comunitarismo e Igualitarismo}

Jamás una cuestión como la integración de los inmigrantes ha desgarrado tanto los medios políticos e intelectuales europeos. Todos los miembros de la Unión Europea 
hacen la misma reflexión: hay que buscar la manera de actuar y cada uno intentar encontrar mecanismos para integrar mejor las minorías étnicas.

Existen en Europa dos modelos de integración opuestos heredados de la historia, el modelo "comunitario" a la británica, y el modelo "igualitario" a la francesa. De tradición liberal, el pluralismo británico se apoya en los cuerpos, los grupos particulares, las órdenes. Este sistema llamado "comunitarista", reconoce la existencia de grupos humanos específicos cuyos representantes negocian con los poderes públicos para obtener derechos particulares. A la inversa, la concepción unitaria y jacobina de la ciudadanía que se ha impuesto en Francia con la Revolución pretende limar las particularidades para una mejor "asimilación". Ella exige de los individuos de origen extranjero que abandonen sus especificidades para disolverse en la sociedad.

Idealista, el "igualitarismo" francés no impide la realidad del racismo o de la discriminación en el empleo. Francia prohibiéndose dar el pequeño empujón a los negros, los magrebíes, los turcos o los asiáticos, asume el riesgo de aumentar sus frustraciones y de empujarlos hacia el "comunitarismo" que pretende combatir (los últimos acontecimientos de violencia callejera en Francia son un ejemplo del fracaso de su política de integración).

Por otro lado, el "comunitarismo" inglés no está exento de efectos perversos. Este alienta la yuxtaposición de comunidades que se ignoran, haciendo difícil la convivencia y casi imposible el reparto de un referencial de valores comunes.

España, Suecia, Holanda, Alemania, Reino Unido,... cada país ajusta su política de integración en función de las medidas de los límites y de los excesos de su propio dogma.

Gran Bretaña, desde los años setenta, empezó a trabajar por la igualdad racial incrementando su arsenal jurídico para luchar contra las discriminaciones en el empleo. Es el país que ha sabido sin duda, más que otros, ofrecer una mayor viabilidad a sus conciudadanos de origen extranjero, alzando a algunos de sus representantes a puestos de responsabilidad. La Ley de Relaciones Raciales llamada Race Relations Amendment Act, entrada en vigor en abril del 2001, permite a ciertas ONGs (como la Operation Black Vote) exigir a un organismo público que rinda cuentas de su política de integración.

En Alemania, a pesar de sus 7,5 millones de extranjeros (cifras del 2004), 2,5 millones son turcos, el debate sobre la integración no está en el orden del día. De hecho, la sociedad empieza a tomar conciencia de que sus inmigrantes, considerados hasta ahora como "trabajadores invitados", van a quedarse. Pero a pesar de ser el país europeo con mayor número de inmigrantes, la no existencia de guetos garantiza una paz social en los barrios.

En Bélgica, desde la creación del Centro antirracista, en 1993, que publica los informes sobre los progresos conseguidos, las mentalidades van evolucionando. Suecia, país de inmigración reciente, desde los años 1970, posee un millón de extranjeros para una población de 9 millones. La integración es un tema de debate recurrente. Holanda, en donde la situación es comparable a la del Reino-Unido, cerca del 10\% de los diputados es de origen extranjero.

En cuanto a los países mediterráneos, que antaño eran comarcas de emigración, son en la actualidad tierras de inmigración. España es el primer destino de los flujos migratorios que entran en la Unión Europea. Con 2.597.014 de extranjeros (estadística de la Secretaria de Inmigración y Emigración, septiembre de 2005), principalmente marroquíes y latinoamericanos, y cerca de la mitad de ellos residentes ilegales, las 
autoridades no tienen mas remedio que resolver la ecuación: “Inmigración” (¿Quién?) + "Integración” (¿Cómo?) = "Paz social” (¿Para qué resultado?).

El índice, reflejado en el gráfico siguiente, no mide el éxito o el fracaso de la integración de los inmigrantes en los países de la UE-15, sino hasta qué punto la legislación les trata como ciudadanos. También cabe señalar que el índice 2005 no incluye la reciente regularización de 700.000 inmigrantes. Aun así, España ocupa el quinto lugar, por encima de países de larga tradición de acogida a extranjeros.

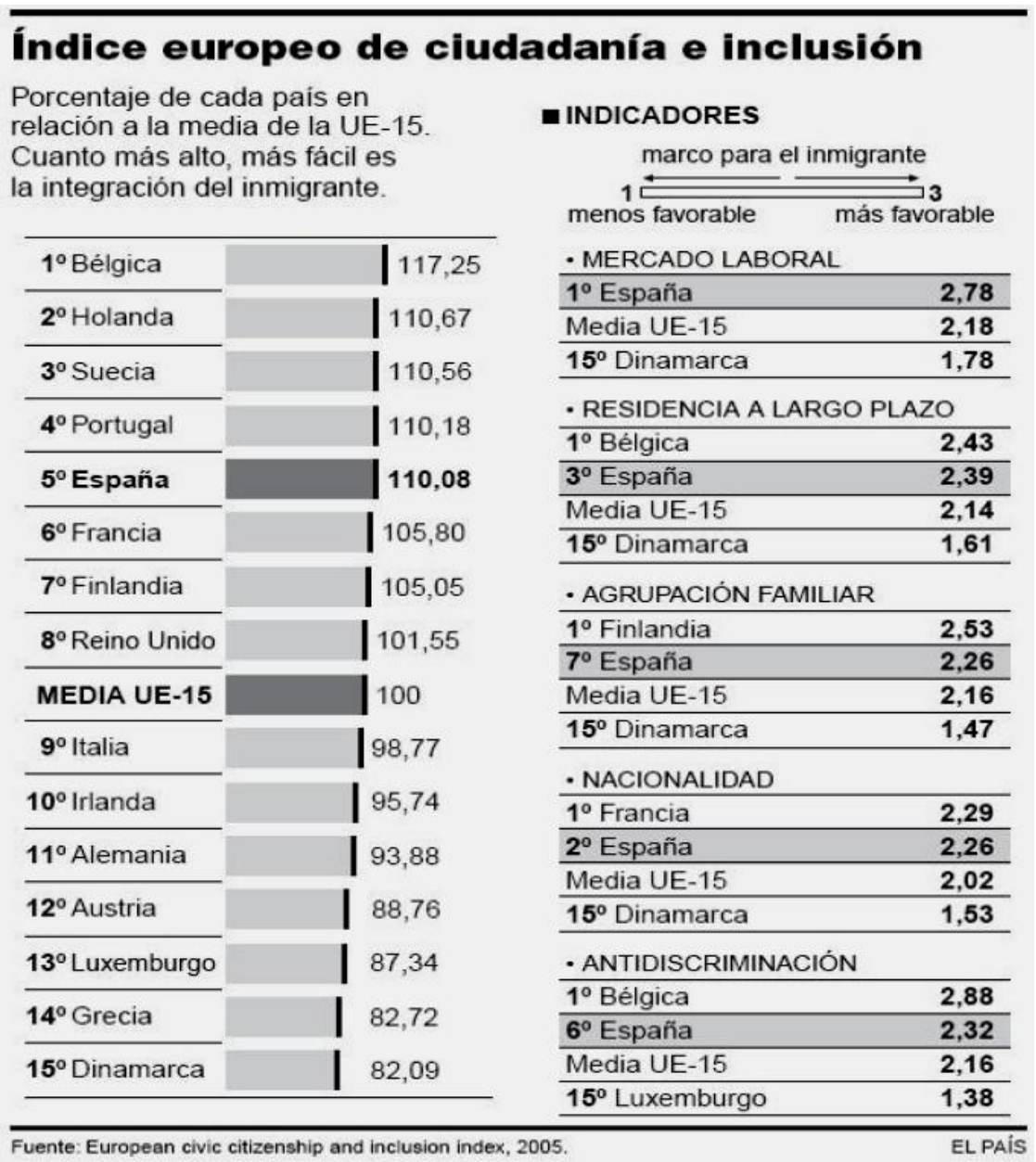

\subsection{El modelo español de integración}

España se ha dotado de un instrumento para la integración de los inmigrantes en el país, estamos hablando del "Foro para la Integración Social de los Inmigrantes", es un órgano colegiado adscrito al Ministerio del Interior a través de la Delegación del Gobierno 
para la Extranjería y la Inmigración, cuya finalidad es la de servir a la participación y la integración de los inmigrantes legalmente establecidos en España. El Foro es la consecuencia de lo establecido en las leyes Orgánicas 4/2000 y 8/2000 respectivamente sobre derechos y libertades y sobre la integración social. El Foro es una entidad de consulta, información y asesoramiento del Gobierno $\mathrm{y}$, en su caso, de las Administraciones autonómicas y locales en materia de inmigración.

La integración de los inmigrantes es una cuestión ampliamente debatida por los políticos y los intelectuales (existe en varias autonomías: Andalucía, Cataluña, Valencia,... Planes de Integración del inmigrante). Hoy existe una voluntad popular de integrar a los extranjeros dice Miguel Azurmendi, profesor de antropología y antiguo Director del Instituto Cervantes de Tánger. Sin embargo, la realidad de las condiciones de vida de los distintos colectivos que forman la población inmigrante en España tiene todos los rasgos de una integración cuyas características generales se resumen en materia de:

1. Educación: en términos de integración socio-cultural no existen problemas mayores. Los hijos de los inmigrantes están incorporados a los colegios públicos. Las distintas comunidades extranjeras han creado redes de solidaridad que asisten al recién llegado. Sin embargo, hay diferencias importantes según los colectivos, sobre todo entre los latinoamericanos y los magrebíes, y según las regiones de asentamiento.

2. Empleo: el inmigrante, con o sin papeles, se integra en un segmento del mercado laboral caracterizado por la inestabilidad, la desregulación, los bajos salarios, la falta de cualificación, y la dureza del trabajo. Para el inmigrante, mantener el puesto de trabajo es sinónimo de permiso de residencia, lo cual significa su permanencia legal en el país.

3. Vivienda: es un factor relevante de discriminación. En el campo o en la ciudad las condiciones de vivienda de los inmigrantes se caracterizan en gran medida por la insalubridad, y en el caso de la ciudad, por un alto coste. A este último problema se unen los recelos xenófobos de muchos propietarios de pisos. Como en el tema de la educación, las diferencias son notables entre los colectivos latinoamericanos y los magrebíes.

4. Salud: los trabajadores extranjeros que residen legalmente en España, con permiso de trabajo y en situación de alta en Seguridad Social, son los únicos que se benefician de la asistencia sanitaria en igualdad de condiciones con los españoles. El resto de extranjeros, aún en situación regular, tienen acceso al sistema publico de salud de forma muy desigual y dependiendo en gran medida de su nivel de educación, el tipo de atención médica que requieran y el lugar de asentamiento.

\section{A MODO DE CONCLUSIÓN}

Se puede decir que España está en un cruce de caminos en cuanto al problema de la integración de los inmigrantes que residen en su territorio. En algunos aspectos está por encima de otros países europeos con más experiencia sobre este fenómeno. Una actitud sabia para hacer frente al problema desde una perspectiva de integración social sería aprender de los errores cometidos en toda Europa, lo que es bueno fomentar y lo que hay que evitar, evitar pues: la creación de zonas de población de inmigrantes marginadas 
(guetos) como en Francia o la yuxtaposición de comunidades que, en el Reino-Unido, viven vidas paralelas sin mezclarse; en Alemania, el sentimiento de pertenencia étnica; en Holanda, cuya cara opuesta es Dinamarca, los limites de una política de tolerancia que se asimila a una indiferencia.

También puede ser que la solución al problema de la integración de los inmigrantes no esté precisamente en obstinarse en buscar la paz social a través de la integración sino más bien desde una perspectiva de buscar la mejor manera para que los inmigrantes "interactúen” más y mejor con la sociedad de acogida, lo que permitirá aumentar el conocimiento mutuo y valorizar la interculturalidad, verdaderos motores del desarrollo y de la paz.

\section{BIBLIOGRAFÍA}

AKELLAL, A. (1999) : "Les motivations historiques et sociales de l'émigration marocaine", en L'émigration marocaine, Rabat : Publications de l'Académie du Royaume du Maroc.

ALVIRA, F. y GARCÍA, J. (2003): “Opinión pública e inmigración”, Papeles de Economía Española, no 98, pp. 182-198.

ARANGO, J. (2003): “Europa, ¿una sociedad multicultural en el siglo XXI?”, Papeles de Economía Española, $\mathrm{n}^{\circ}$ 98, pp. 2-16.

AUBRY, M. (2006): "Immigration, comprendre, construire", Ed. De l'Aube, Collection Alternatives Sud (2004). Genèse et enjeux des migrations internationales. Paris.

BARCIELA, F. (2004): "La utópica búsqueda del equilibrio inmigratorio", Revista Economía Exterior, $\mathrm{n}^{\mathrm{o}} 28$, pp. 115-129.

DÍEZ NICOLÁS, J. (1999): Los españoles y la inmigración, Madrid, IMSERSO.

EL MOUHOUB, M. (2005): Les nouvelles migrations: un enjeu Nord-Sud de la mondialisation, Paris, Ed. Universalis.

GONZÁLEZ FERRERA, G. y col. (2006): Estudio sobre la situación de las mujeres a ambos lados del Estrecho de Gibraltar, Sevilla, Instituto Andaluz de la Mujer.

- (2008): Identificación y caracterización de los principales flujos migratorios en el norte de Marruecos, PROYECTO OMEPEI, iniciativa INTERREG III A. (Próxima publicación)

I PLAN INTEGRAL PARA LA INMIGRACIÓN EN ANDALUCÍA. 2001-2004 (2005): Edita Dirección General de Coordinación de Políticas Migratorias, Sevilla, Junta de Andalucía.

MÉDICOS SIN FRONTERAS (2005): Informe sobre la inmigración de origen subsahariano en situación irregular en Marruecos, MDF-E.

SAMI, N. (2000): El peaje de la vida, Madrid, Aguilar/ Ediciones El País.

SOREL, A. (2000): Las voces del Estrecho, Barcelona, Muchnik Editores.

VILLENA RODRÍGUEZ, M. (2004): Demografía, mercado de trabajo y política de inmigración,

Eumed.net.

\section{SITIOS WEB}

El Mundo. "Inmigrantes. En busca de futuro" $<$ http://www.elmundo.es/sociedad/inmigración $>$ http://www.aidex.es/observatorio/temas/inmigracion/indiceinmigracion.htm http://www.eumed.net/cursecon/libreria/2004/mvr/index.htm http://www.extranjeros.mtas.es http://www.estudis.lacaixa.comunicacions.com/webes/estudis.nsf/wurl/pfes008cos_esp http://www.izquierda-unida.es/Publicaciones/InmigracionyAsilo/inmigracion4.htm http://www.intermigra.info/extranjeria/ 
http://fpc.org.uk/fsblob/513.pdf

http://www.europa.eu.int

$\mathrm{http}: / / \mathrm{www}$. extranjerossinpapeles.com

\section{Breve currículo:}

\section{Jamal Benamar}

Profesor de Comunicación, Departamento de Economía, Facultad de Derecho, Universidad Abdelmalek Essaâdi (Tánger). Miembro de la comisión científica de la Facultad. Responsable del Master "Gestión de las Organizaciones". Responsable de numerosos proyectos de investigación con Universidades españolas: "Análisis comparativo de datos estadísticos con perspectiva de género entre el Norte de Marruecos y el Sur de España", "Desarrollo económico y enriquecimiento cultural con perspectiva de género", "Análisis de las topologías y las características de los flujos migratorios entre Marruecos y España", "Gestión y Desarrollo estratégico de la calidad en el turismo y los ocios", "La identidad femenina en la sociedad marroquí actual", "Los indicadores de sostenibilidad y el turismo de Arsilah y su entorno (Marruecos)". Iniciador y redactor del proyecto: "Las perspectivas del Turismo en la Wilaya de Tánger: ¿Qué producto, para qué puesta en valor?". Autor de varias publicaciones de carácter pedagógico y de artículos sobre: inmigración, turismo, desarrollo sostenible. Fundador del Grupo de Investigación en Métodos cuantitativos de la Facultad. Miembro del comité científico de la revista Tingis de la Facultad. Director del grupo de investigación en Comunicación y las NTIC. 